\title{
STRAIGHT FROM THE GUT
}

S tephanie is the first to admit that she never had the guts for life. She was born with familial adenomatous polyposis, a genetic disorder in which thousands of polyps form in the colon. By the age of 22, much of the organ had to be removed. Four years later, a massive benign tumour choked off the blood supply to her small intestine, so doctors cut out all but a metre of it. For the next six years, she was fed by a tube every night until the feeding left her liver badly scarred and fighting recurring infections. "I was given a month to live," she says.

That's when doctors referred Stephanie to Georgetown University Hospital in Washington DC. There, on 17 April 2006, surgeons cut out her stomach and what was left of her small and large intestine and replaced it with new organs from a donor who had died days earlier in Tennessee. "Oesophagus to anus, her entire gastrointestinal tract was in the garbage can," says Tom Fishbein, who directed the surgery. "She got a brand new one."

All organ transplants are complicated, but there are only a handful of centres in the United States that have the expertise to transplant a small intestine, the

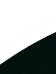

seven metres of coiled tissue connected up to the stomach at one end and the large intestine at the other. The technique is complicated because the gut is teeming with trillions of bacteria and other microbes, plus the bulk of the body's lymphocytes. Before such transplants, the donor's intestine has normally been flushed with antibiotics. But rates of infection and rejection from such transplants are very high because, it is thought, some foreign bacteria and immune cells survive the cleaning process and are thrust into an immunosuppressed recipient.

The idea that these intestinal bacteria are a menace is now under review. By teaming up with microbiologists, the surgeons are taking advantage of a rare chance to study microbes as they colonize the walls of the gut after transplanting an intestine: which ones arrive first, and how they restore the ravaged microbial communities. "An all new ecosystem of organisms had to populate that bowel from scratch," says Fishbein. Their new appreciation of that ecosystem, along with their growing surgical experience, suggests that the populations might e better left intact before a nsplant.

The same studies may also offer insight into

Dirty business: gut transplants give bacteria and scientists new choices. how the gut is first populated by microbes after birth, how it recovers from the damage done by a heavy course of antibiotics and, perhaps, how to minimize that damage. "Most people study this in animal models, but this is a real-person model," says Brett Finlay, a microbiologist at the University of British Columbia in Vancouver, Canada. "It's an artificial system in some sense, but it's a neat model."

How the moist, pink intestinal tubing lives in such harmonious contact with bacteria has puzzled scientists for decades. But "it's hard to get in there, especially in a healthy person", says David Relman, who studies microbiology and immunology at Stanford University, California. "And to do it in a way that doesn't perturb the system, and to do it every week or every day, well, forget it." For this reason, most researchers interested in the contents of human innards have had to collect and filter faeces.

\section{Beautiful opportunity}

The transplant scenario is a unique and attractive alternative. For the first few months after an operation, the end of the gut that would normally go into the rectum is left poking out of the abdomen so that doctors can check the transplant is stable. As often as necessary, doctors can probe this stoma, or opening, 
